University of Nebraska - Lincoln

DigitalCommons@University of Nebraska - Lincoln

Faculty Publications from the Department of Electrical \& Computer Engineering, Department Electrical and Computer Engineering

9-19-1994

\title{
Complex index-of-refraction measurements for RP-1 liquid rocket fuel
}

Dennis R. Alexander

University of Nebraska-Lincoln, dalexander1@unl.edu

Ramu Kaiwala

University of Nebraska-Lincoln

Robert D. Kubik

University of Nebraska-Lincoln

Scott A. Schaub

Schuller International

Follow this and additional works at: https://digitalcommons.unl.edu/electricalengineeringfacpub

Part of the Computer Engineering Commons, and the Electrical and Computer Engineering Commons

Alexander, Dennis R.; Kaiwala, Ramu; Kubik, Robert D.; and Schaub, Scott A., "Complex index-of-refraction measurements for RP-1 liquid rocket fuel" (1994). Faculty Publications from the Department of Electrical and Computer Engineering. 552.

https://digitalcommons.unl.edu/electricalengineeringfacpub/552

This Article is brought to you for free and open access by the Electrical \& Computer Engineering, Department of at DigitalCommons@University of Nebraska - Lincoln. It has been accepted for inclusion in Faculty Publications from the Department of Electrical and Computer Engineering by an authorized administrator of DigitalCommons@University of Nebraska - Lincoln. 


\section{Complex index-of-refraction measurements for RP-1 liquid rocket fuel}

\author{
Dennis R. Alexander, MEMBER SPIE \\ University of Nebraska-Lincoln \\ Center for Electro-Optics \\ and \\ Electrical Engineering Department \\ Lincoln, Nebraska 68588-0511 \\ E-mail: alex@indigo1.unl.edu \\ Ramu Kalwala \\ University of Nebraska-Lincoln \\ Center for Electro-Optics \\ and \\ Department of Mechanical Engineering \\ Lincoln, Nebraska 68588-0656 \\ Robert D. Kubik \\ University of Nebraska-Lincoln \\ Center for Electro-Optics \\ and \\ Electrical Engineering Department \\ Lincoln, Nebraska 68588-0511 \\ Scott A. Schaub \\ Schuller International \\ 10100 West Ute Avenue \\ Littleton, Colorado 80162-5005
}

\begin{abstract}
Complex index-of-refraction values of RP-1 liquid rocket fuel are reported at laser wavelengths of $0.193 \mu \mathrm{m}$ (ArF excimer), 0.4765 $\mu \mathrm{m}$ (argon ion), $0.488 \mu \mathrm{m}$ (argon ion), $0.5145 \mu \mathrm{m}$ (argon ion), $0.532 \mu \mathrm{m}$ (Nd-YAG, frequency doubled), $0.6328 \mu \mathrm{m}$ (He-Ne), $1.064 \mu \mathrm{m}$ (Nd-YAG), and $10.5915 \mu \mathrm{m}\left(\mathrm{CO}_{2}\right)$. The imaginary part of the index of refraction $(k)$ is determined by traditional transmission methods. The real part $\left(n_{r}\right)$ at the specific laser lines is determined using reflectance measurements, critical-angle measurements, Mueller matrix elements, and Michelson interferometric measurements. Reflectance measurements are used to obtain $n_{r}$ at a wavelength of $0.193 \mu \mathrm{m}$. The critical-angle method is used to determine $n_{r}$ at $0.4765,0.488,0.5145$, and $0.532 \mu \mathrm{m}$ : the real part of the refractive index is obtained from Snell's law by measuring the critical angle. The real part of the refractive index at 0.6328 and $1.064 \mu \mathrm{m}$ is derived from elements of the Mueller matrix, which are obtained using a TMA Technologies scatterometer. A Michelson interferometer is used to obtain phase shifts in a wedge cell, which are then used to calculate $n_{r}$ at $10.5915 \mu \mathrm{m}$. The need for many methods to measure the complex index of refraction is a result of the large changes in $k$ over the wavelengths of interest.
\end{abstract}

Subject terms: refractive indices; laser ignition; fuel sprays; transmission; reflection; critical angle; Mueller matrix; Michelson interferometer.

Optical Engineering 34(3), 913-921 (March 1995).

\section{Introduction}

Knowledge of the refractive indices of certain materials is of great importance in many engineering and scientific applications. For example, optical constants are needed to calculate the focusing of a laser beam used to ignite rocket fuel inside an engine. These optical parameters are not directly measurable but can be derived from measured quantities such as the transmission and reflection coefficients. There are several methods available to determine the optical constants of materials, such as the angle of deviation, ${ }^{1,2}$ the critical-angle technique, ${ }^{3,4}$ and reflection and transmission measurements. ${ }^{5-8}$ Most of these methods rely on specific experimental procedures.

In this paper we determine the refractive indices of RP-1 liquid rocket fuel at eight wavelengths $(0.193,0.4765,0.488$, $0.5145,0.532,0.6328,1.064$, and $10.5915 \mu \mathrm{m})$. Five separate methods were used to perform the real-part measurements,

Paper 30054 received May 21, 1994; revised manuscript received Sep. 19, 1994; accepted for publication Sep. 19, 1994.

(C) 1995 Society of Photo-Optical Instrumentation Engineers. 0091-3286/95/\$6.00. since there was a large variation in the imaginary part of the index of refraction, which made some of the methods not feasible at certain wavelengths. For the imaginary part at $0.193 \mu \mathrm{m}$, transmission measurements were taken through a quartz cell with $0.1-\mathrm{mm}$ thickness using a spectrophotometer. At the remaining wavelengths, transmission measurements were carried out using a variable-path-length technique. When a laser beam is incident on a cell that holds a liquid, and passes through it, the amount of energy transmitted through the liquid is exponentially related to the liquid path length. Since we know the relation between $k$ and the attenuation coefficient, the transmission power of the laser beam through the liquid can be measured at various path lengths to find the attenuation coefficient.

For determining the real part of the refractive index of RP-1, reflectance measurements, critical-angle measurements, determination of the Mueller matrix elements using a scatterometer, and Michelson interferometric measurements were used. Reflectance measurements were taken at and near normal incidence to determine $n_{r}$ at $0.193 \mu \mathrm{m}$. The need for this method was due to the high absorption of the liquid at $0.193 \mu \mathrm{m}$. Critical-angle measurements were used 
at laser wavelengths of $0.4765,0.488,0.5145$, and $0.532 \mu \mathrm{m}$. The critical angle is the incident angle for which the transmitted angle is $90 \mathrm{deg}$. By measuring the critical angle we determined the real part of the refractive index of the liquid. Mueller-matrix values along with corresponding ellipsometric parameters [see Eqs. (12), (13)] are used to find $n_{r}$ at 0.6328 and $1.064 \mu \mathrm{m}$. The Mueller-matrix values are obtained using a TMA scatterometer by measuring the incident angle, incident intensities, and reflection intensities for different laser-beam incident angles on the surface of the liquid. The TMA scatterometer is designed for the sample to be held in a horizontal position, while ellipsometers at the University of Nebraska only accommodate samples held in the vertical position. Furthermore, scatterometers determine all sixteen elements of the Mueller matrix, while an ellipsometer determines only four of the sixteen. Large incident angles were considered for specular measurements. In addition, the scatterometer has maximum experimental sensitivity at large incident angles. By computing the ellipsometric parameters, based on the Mueller matrix elements, we determine the refractive indices of the liquid. We did not consider this method to determine $k$, because system errors of the scatterometer dominate the measurement of $k$, especially for small $k$ ( $k \leqslant$ $0.01)$. At $10.5915 \mu \mathrm{m}\left(\mathrm{CO}_{2}\right.$ waveguide laser, Laser Photonics model CL75), a thin wedge-shaped cell was used to hold the liquid and was placed in one arm of a Michelson interferometer. This cell was moved perpendicular to a $\mathrm{CO}_{2}$ laser beam so as to present a variable path length through the liquid being tested. Michelson interferometer fringe shifts were used to determine $n_{r}$, while transmission power measurements through the same cell were used to determine $k$ at this wavelength.

\section{Basic Theory for Measurements}

\subsection{Imaginary Part of the Index of Refraction}

The imaginary part of the refractive index represents the amount of energy absorbed by the liquid when light passes through it. The amount of energy transmitted through the liquid is exponentially related to the liquid path length $y$ as

$I_{1}(y)=I_{0} \exp (-\alpha y)$,

where $I_{0}$ is the initial irradiance, $I_{1}$ is the irradiance at $y$, and $\alpha$ is the attenuation coefficient. This attenuation coefficient is directly proportional to the imaginary part of the refractive index. The measured irradiances at two different liquid path lengths were expressed as

$I_{1}\left(y_{1}\right)=I_{0} \exp \left(-\alpha y_{1}\right)$,

$I_{2}\left(y_{2}\right)=I_{0} \exp \left(-\alpha y_{2}\right)$.

The irradiances $I_{1}$ and $I_{2}$ are known values at known path lengths $y_{1}$ and $y_{2}$, and from Eqs. (2) and (3).

$\alpha=\frac{1}{y_{2}-y_{1}} \ln \left(\frac{I_{1}}{I_{2}}\right)$.

The relation between $\alpha$ and $k$ is

$\alpha=\frac{4 \pi k}{\lambda}$,

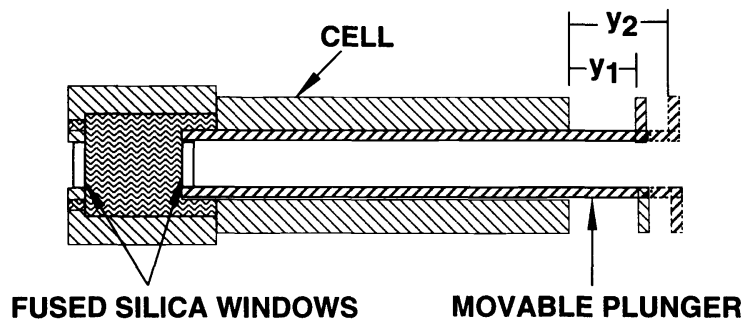

Fig. 1 Schematic diagram of the test cell used at $0.4765,0.488$, $0.5145,0.532,0.6328$, and $1.064 \mu \mathrm{m}$.

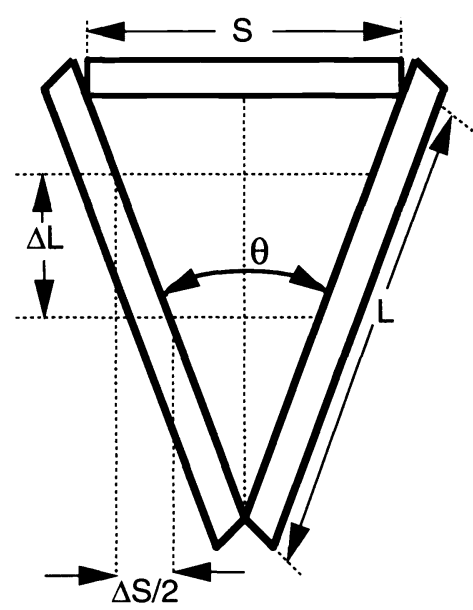

Fig. 2 Schematic diagram of the thin wedge-shaped cell used at $10.5915 \mu \mathrm{m}$.

where $\lambda$ is the wavelength of the laser light in air. From Eqs. (4) and (5),

$k=\frac{\lambda}{4 \pi\left(y_{2}-y_{1}\right)} \ln \left(\frac{I_{1}}{I_{2}}\right)$.

For measuring the imaginary part of the refractive index of the liquid, a schematic diagram of the test cell is shown in Fig. 1. This cell contains two fused-silica windows (30-mm diam), one fixed to the cell and the other fixed to the movable plunger. To seal the space between the cell and the movable plunger, two $\mathrm{O}$ rings were fixed on the outer diameter of the plunger. Different liquid path lengths were obtained by moving this plunger. As shown in Fig. 1 , the irradiances $I_{1}$ and $I_{2}$ were measured at liquid path lengths of $y_{1}$ and $y_{2}$, respectively. A micrometer was used to measure the liquid path lengths.

A thin wedge-shaped cell was used to measure the refractive indices of RP-1 at $10.5915 \mu \mathrm{m}$ and is shown in Fig. 2 . This cell was made with two $\mathrm{ZnSe}$ windows. These windows are in physical contact at one end, and are separated at the other end by a thin piece of material.

\subsection{Real Part of the Index of Refraction}

Since RP-1 is highly absorbing at $0.193 \mu \mathrm{m}, n_{r}$ could only be measured using a reflectance method. The reflectance $R$ can be derived using Fresnel and Snell's laws. It is given by ${ }^{6}$ 
$R_{\perp}=\frac{\cos ^{2} \theta+\mu^{2} A-2 \mu A^{1 / 2} \cos \theta \cos B}{\cos ^{2} \theta+\mu^{2} A+2 \mu A^{1 / 2} \cos \theta \cos B}$

$R_{\|}=$

$$
\frac{\mu^{2}\left(C^{2}+D^{2}\right) \cos ^{2} \theta+A-2 \mu A^{1 / 2} \cos \theta(C \cos B+D \sin B)}{\mu^{2}\left(C^{2}+D^{2}\right) \cos ^{2} \theta+A+2 \mu A^{1 / 2} \cos \theta(C \cos B+D \sin B)},
$$

where $A=\left[\left(n_{r}^{2}-k^{2}-\sin ^{2} \theta\right)^{2}+4 n_{r}^{2} k^{2}\right]^{1 / 2}, \quad B=0.5 \quad \tan ^{-1}$ $\left[2 n_{r} k /\left(n_{r}^{2}-k^{2}-\sin ^{2} \theta\right)\right], C=n_{r}^{2}-k^{2}, D=2 n_{r} k, \mu=1, \theta$ is the incident angle, and $k$ is the known imaginary value determined from transmission measurements. Since the measured reflected light will not be polarized in the same way as the incident laser light, the reflectivity for the unpolarized reflected light is

$R_{u}=\frac{1}{2}\left(R_{\perp}+R_{\|}\right)$

The real part of the refractive index was determined by trial and error using Eq. (9). This method involves an approximate calculation of $n_{r}$ by comparing an experimentally known value of $R_{u}$ with a value obtained from Eq. (9). An approximate value of $n_{r}$ is substituted in Eq. (9) to get $R_{u}$. If the obtained value of $R_{u}$ is not equal to the experimental value, $n_{r}$ must be approximated again to get a new solution. This trial-and-error procedure continues until the value of $R_{u}$ obtained from Eq. (9) is equal to the known experimental value.

Critical-angle measurements were used to determine $n_{r}$ at $0.4765,0.488,0.5145$, and $0.532 \mu \mathrm{m}$. From Snell's law,

$\sin \theta_{c}=\frac{n_{t}}{n_{r}}$,

where $\theta_{c}$ is the critical angle and $n_{t}$ is the refractive index of the transmitting medium (air), which is equal to 1.000293.

At $1.064 \mu \mathrm{m}$, the real part of the refractive index is measured using Mueller matrix elements. A scatterometer, manufactured by TMA Technologies, was used to measure the incident angle, incident intensities, and reflection intensities at various polarization states to obtain the Mueller-matrixelement values. The Mueller (phase) matrix is given by 9,10

$M=\left[\begin{array}{llll}m_{11} & m_{12} & m_{13} & m_{14} \\ m_{21} & m_{22} & m_{23} & m_{24} \\ m_{31} & m_{32} & m_{33} & m_{34} \\ m_{41} & m_{42} & m_{43} & m_{44}\end{array}\right]$.

This matrix relates the incident Stokes vector to the scattered Stokes vector. ${ }^{9,10}$ The elements of the Stokes vectors are related to measurable quantities (see, e.g., Ref. 9 for details). Corresponding ellipsometric parameters $\psi$ and $\Delta$ are obtained from the Mueller matrix elements:

$\psi=\frac{1}{2} \arccos \left(\frac{m_{12}+m_{21}}{m_{11}+m_{22}}\right)$,
$\Delta=\arctan \left(\frac{m_{34}-m_{43}}{m_{33}+m_{44}}\right)$,

where $m_{11}, m_{12}, \ldots$ represent the elements of the Mueller matrix. By using the ellipsometric parameters, we can determine the refractive indices of the liquid from the following equations:

$N=n_{r}-j k=\sin \theta\left[1+\left(\tan \theta \frac{1-\rho}{1+\rho}\right)^{2}\right]^{1 / 2}$,

$\rho=\tan \psi \exp (j \Delta)$

where $N$ is the complex refractive index of the liquid, $\theta$ is the incident angle, $\rho$ is the ellipsometric function, and $\psi$ and $\Delta$ are the ellipsometric angles (for a complete discussion of $\rho, \psi$, and $\Delta$, the reader is referred to Refs. 9 and 10).

As shown in Fig. 2, a thin wedge-shaped cell was used to measure $n_{r}$ at $10.5915 \mu \mathrm{m}$ by using a Michelson interferometer. From Fig. 2,

$$
\frac{\theta}{2}=\sin ^{-1}\left(\frac{S}{2 L}\right) \text {, }
$$

and the change in the thickness of the liquid, $\Delta S$, is given by

$\Delta S=2 \Delta L \tan (\theta / 2)$,

where $\Delta L$ is the change in the length of the cell. By counting the fringes that move across the viewing screen as the cell is moved, we calculate $n_{r}$. For one fringe change on the viewing screen, there must be a phase shift of $2 \pi$. The equation relating the phase shift to the change in the thickness of the liquid is

$2 \pi m=2\left(\frac{2 \pi}{\lambda_{r}} \Delta S-\frac{2 \pi}{\lambda_{0}} \Delta S\right)$,

where $m$ is the number of fringes, and $\lambda_{0}$ and $\lambda_{r}$ are the wavelengths of the laser light in air and in the liquid, respectively. Since

$\lambda_{r}=\frac{\lambda_{0}}{n_{r}}$

Eq. (18) reduces to

$n_{r}=\frac{m \lambda_{0}}{2 \Delta S}+1$

\section{Experimental Setup}

The experimental setup for measurement of both real and imaginary parts of the index of refraction is different at each wavelength. All measurements except for the TMA scatterometer measurements are performed on research-grade $4 \times 12$-ft Newport Research, Inc. optical vibration tables.

Figure 3 describes the experimental setup at $0.193 \mu \mathrm{m}$. To determine the imaginary part of the refractive index, trans- 


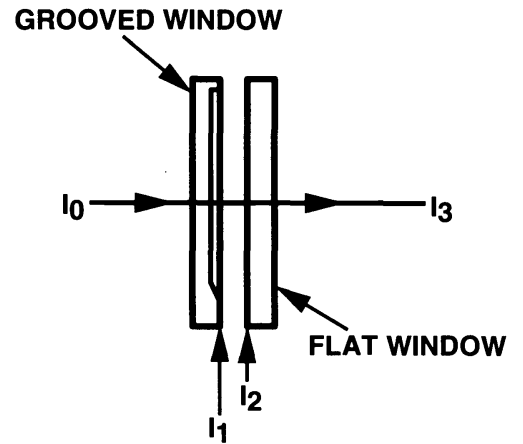

(a)

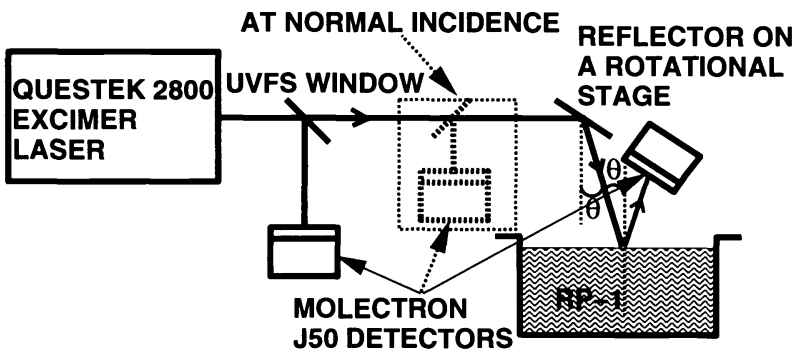

(b)

Fig. 3 Experimental setup at $0.193 \mu \mathrm{m}$ : quartz cell for (a) imaginary part and (b) real part.

mission measurements were carried out on a Lambda 9 spectrophotometer (manufactured by Perkin-Elmer) by using a quartz cell with $0.1-\mathrm{mm}$ thickness. Figure 3(a) is a schematic of the quartz cell used to measure the imaginary part of the refractive index with a spectrophotometer. To determine $n_{r}$ at this wavelength, reflectance measurements are carried out using a Questek 2860 series excimer laser with the beam at and near normal incidence. The typical pulse length of this laser is $17 \mathrm{~ns}$ full width at half maximum (FWHM), and low repetition rates of $5 \mathrm{~Hz}$ were used to avoid heating of the RP-1. Figure 3(b) shows the experimental setup. As shown, a UV-grade fused-silica window was used to separate out part of the beam, which was used to normalize the power of the laser beam. This step is taken due to the large variations in power of the laser. A reflector (manufactured by Acton Research Corporation) was used to send the beam downward onto the free surface of the liquid and to set the incident angle on a rotational stage. For the measurements at normal incidence, one beamsplitter was placed between the window and the reflector. This step was taken to separate out part of the reflected beam from the incident beam to measure the reflection intensity. Also, a Tektronix AM502 differential amplifier was connected between the detector and power meter to amplify the signal in order to obtain better resolution on the power meter. The incident and reflected power were measured using a Hewlett-Packard model 54200A digital oscilloscope and two Molectron detectors (model J50), which have a rise time of $3 \mathrm{~ms}$ and a maximum pulse repetition rate of 10 pps.

Figure 4 is a schematic of the experimental setup for measurements performed at $0.4765,0.488$, and $0.5145 \mu \mathrm{m}$. For the imaginary-part measurements, the beam of a Liconix 5304-AN argon laser is incident on the cell (Fig. 1) that holds

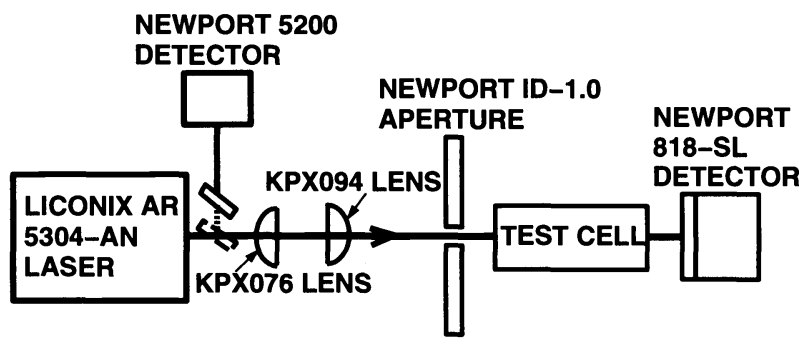

(a)

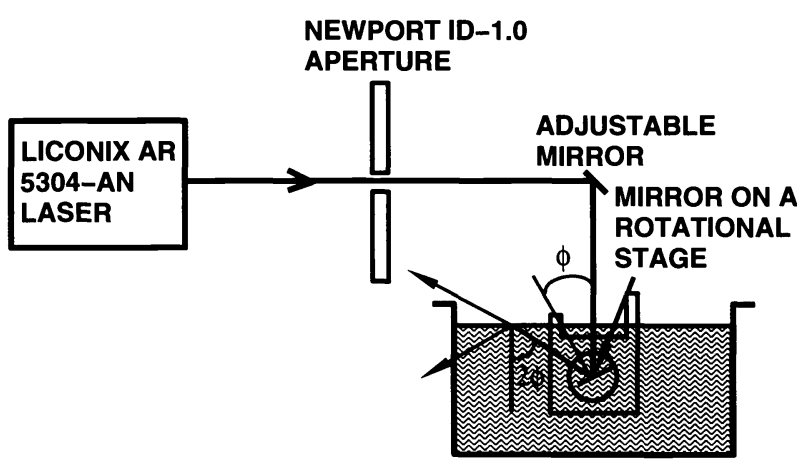

(b)

Fig. 4 Experimental setup at $0.4765,0.488$, and $0.5145 \mu \mathrm{m}$ : (a) imaginary part and (b) real part.

the RP-1. As shown in Fig. 4(a), a Newport Research KPX076 lens and a KPX094 lens along with a variable iris are placed between the laser head and the test cell to form a collimated beam. The test cell is fixed so that the reflections do not interfere and the laser beam is incident on the central portion of the cell windows. The open end of the cell and the top of the movable plunger are marked so that the plunger can be rotated to the same position for each measurement. This is done to avoid any changes in the transmitted-beam position on the power detector. As the beam passed through the test cell, the power of the transmitted beam was measured by using a Newport detector (model 818-SL). Three or four sets of measurements were taken at $0.4765,0.488$, and 0.5145 $\mu \mathrm{m}$.

Figure 4(b) is a schematic of the experimental setup for measuring the real part of the refractive index. Here we used a container with two mirrors and a rotational stage. An adjustable mirror was used to direct the collimated beam downward onto the free surface of the liquid as shown. This mirror was placed so that the incident beam is normal to the liquid surface. This can be determined by aligning the reflected light on a pinhole. A second mirror was mounted on the rotational stage and was positioned below the liquid surface. This mirror was adjusted so that the light reflecting from it coincided with the incident beam. The corresponding angle $\phi_{0}$ is measured as a reference point on the rotational stage. The critical angle is measured by rotating the second mirror. As $\phi$ becomes larger, the reflected beam grows stronger while the transmitted beam grows weaker, and at some angle the transmitted beam disappears (total internal reflection). At this point the rotational stage position $\left(\phi_{c}\right)$ is measured. The critical angle is given by the equation $\theta_{c}=2\left(\phi_{c}-\phi_{0}\right)$. 


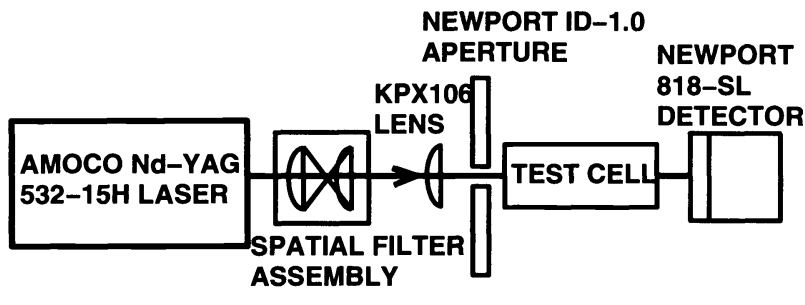

(a)

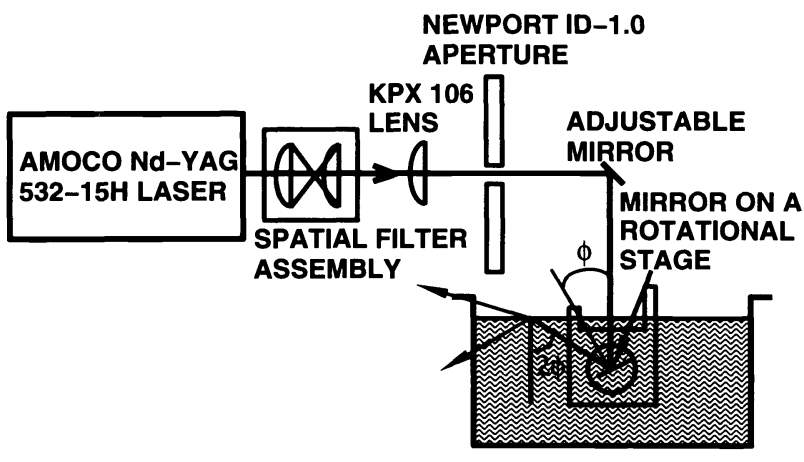

(b)

Fig. 5 Experimental setup at $0.532 \mu \mathrm{m}$ : (a) imaginary part and (b) real part.

The experimental setup used at $0.532 \mu \mathrm{m}$ is schematically shown in Fig. 5. A Nd-YAG laser (continuous wave, Amoco Laser Company model $532-15 \mathrm{H}$ ) operating at $0.532 \mu \mathrm{m}$ is used for the experiment. The imaginary-part measurement is similar to that at $0.4765,0.488$, and $0.5145 \mu \mathrm{m}$. A spatial filter assembly is used to eliminate the unwanted portion of the beam. The remaining experimental procedure is the same as explained above. Three sets of measurements were taken at this wavelength. The measurement of $n_{r}$ [Fig. 5(b)] at 0.532 $\mu \mathrm{m}$ is the same as explained above at $0.4765,0.488$, and $0.5145 \mu \mathrm{m}$.

A polarimetric optical bistatic scatterometer (true angle scatter coordinate) manufactured by TMA Technologies was used to measure the refractive indices of RP- 1 at 0.6328 and $1.064 \mu \mathrm{m}$. This scatterometer is designed so that the transmitter can rotate in an arc in a vertical plane and its receiver can rotate in both vertical and horizontal planes. A He-Ne laser operating at the $0.6328-\mu \mathrm{m}$ line and a Nd-YAG laser operating at the $1.064-\mu \mathrm{m}$ line yield the only two wavelengths available for measurements on this instrument. The imaginary part of the index of refraction at these wavelengths was measured by passing the beams through the variable-pathlength test cell. Three sets of measurements were taken at each wavelength. For the real-part measurements, a clean and open-faced container was used to hold the liquid and is shown in Fig. 6. This container was placed horizontally on the sample holder. Values for the Mueller matrix elements were obtained by directing the laser beam onto the surface of the liquid and detecting the scattered beam for various incident angles. The software package in the scatterometer computes the elements of the Mueller matrix.

Figure 7 is a diagram of the experimental setup for the measurement of the values of both $n_{r}$ and $k$ at $10.5915 \mu \mathrm{m}$. Here we used beamsplitters (manufactured by Newport) be-

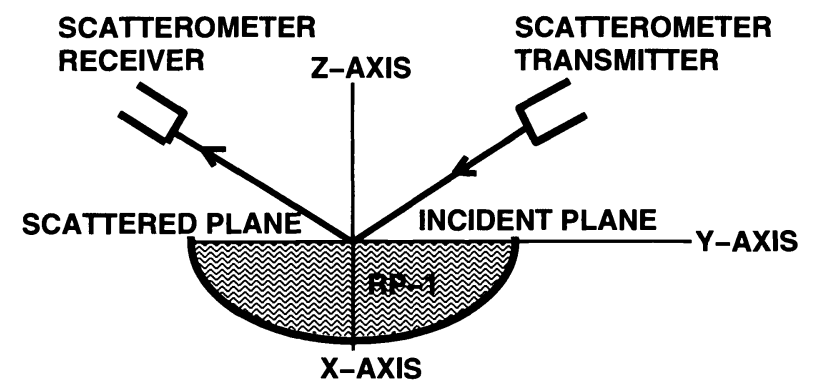

Fig. 6 Experimental setup for $n_{r}$ measurement at 0.6328 and $1.064 \mu \mathrm{m}$.

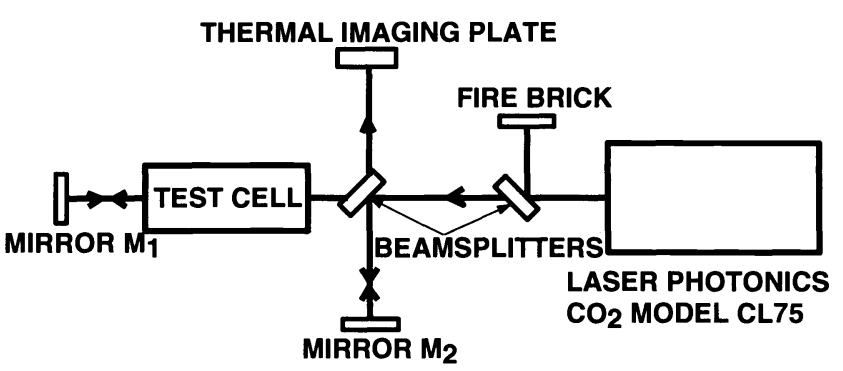

Fig. 7 Experimental setup at $10.5915 \mu \mathrm{m}$.

tween the thin wedge cell and the laser beam to reduce the power of the laser and to produce the fringe pattern. The cell was placed on a translator such that the beam reflected from the front surface of the test cell would not interfere with the Michelson interferometer. Thermal imaging plates (manufactured by Optical Engineering) were used to display the fringe pattern.

\section{Results}

As a preliminary test for the transmission method (variablepath-length technique), three sets of transmission measurements were taken for distilled water at $1.064 \mu \mathrm{m}$. Figure 8(a) shows the transmitted power versus path length. Three or four sets of transmission measurements were taken for RP-1 at each of the wavelengths $0.4765,0.488,0.5145,0.532$, 0.6328 , and $1.064 \mu \mathrm{m}$. For each set, 7 to 14 transmission measurements were taken at different liquid path lengths. Corresponding graphs of the transmitted power versus the liquid path length are shown in Figs. 9, 10, and 11. Table 1 shows the measured reflectances at and near normal incidence for RP-1 $(0.193 \mu \mathrm{m})$ and for distilled water $(0.248 \mu \mathrm{m})$. Tables 2 and 3 show the measured critical angles for the determination of the real part at $0.4765,0.488,0.5145$, and $0.532 \mu \mathrm{m}$. Tables 4 and 5 give measured values for the refractive indices of RP-1 at $10.5915 \mu \mathrm{m}$. Mueller-matrix values at different incident angles for distilled water at $1.064 \mu \mathrm{m}$ and for RP-1 at 0.6328 and $1.064 \mu \mathrm{m}$ are given in Table 6 .

\section{Discussion and Analysis}

In order to determine how well these five methods worked, a sample with a well-known index was measured as a reference. Distilled water was used in this work. Table 7 gives the measured refractive indices of water. The corresponding values of $n_{r}$ from reflectance measurements $(0.248 \mu \mathrm{m})$, 


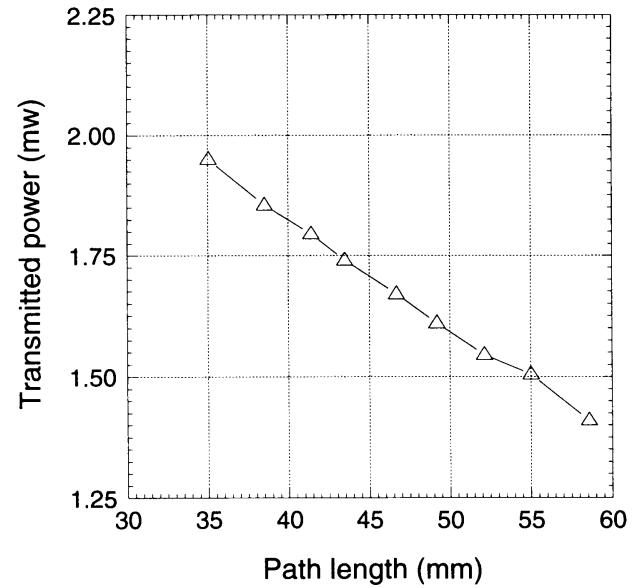

(a)

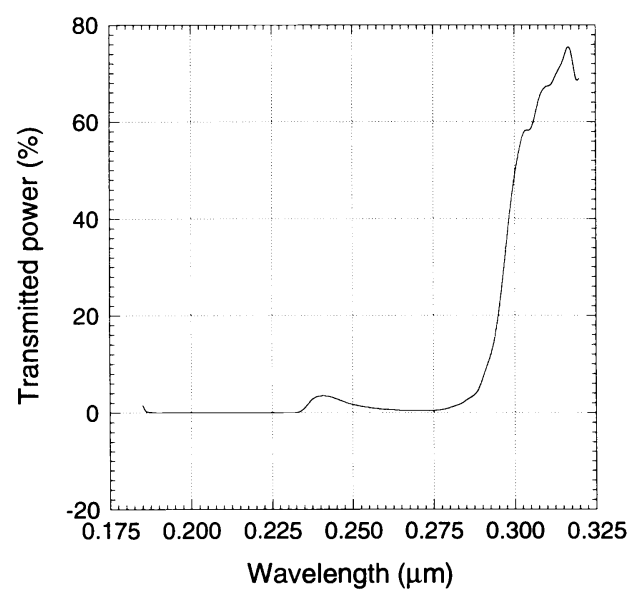

(b)

Fig. 8 Transmission power measurements for $\left(\right.$ a) $\mathrm{H}_{2} \mathrm{O}$ at $1.064 \mu \mathrm{m}$ and (b) RP-1 with a spectrophotometer at various wavelengths.

critical-angle measurements $(0.488 \mu \mathrm{m})$, Michelson interferometric measurements $(0.6328 \mu \mathrm{m})$, and Mueller matrix elements $(1.064 \mu \mathrm{m})$ are $1.364,1.335,1.332$, and 1.328, respectively. The measured value of $k$ at $1.064 \mu \mathrm{m}$ from the transmission method is $1.14 \times 10^{-6}$. This is in good agreement with standard values of $n_{r}$ and $k$ for water. ${ }^{11}$ Measured refractive indices of RP-1 are shown in Table 8 and in Fig. 12. From the data [Fig. 8(b)] obtained on the spectrophotometer, the percentage of power transmitted through the quartz cell filled with RP-1 was found to be $0.02 \%$ at 0.193 $\mu \mathrm{m}$. The measured transmission powers of the grooved and flat windows of the quartz cell were $86.245 \%$ and $86.1 \%$, respectively. The corresponding imaginary part of the refractive index is $1.26 \times 10^{-3}$.

Three or four sets of measurements [Figs. 9 and 10(a)] were carried out on RP-1 at $0.4765,0.488$, and $0.5145 \mu \mathrm{m}$. Average values of $k$ for these wavelengths are $1.31 \times 10^{-7}$, $1.01 \times 10^{-7}$, and $7.86 \times 10^{-8}$ with standard deviations of $\pm 5.49 \times 10^{-9}, \pm 6.07 \times 10^{-9}$, and $\pm 4.01 \times 10^{-9}$, respectively. To get accurate values of $k$, different combinations of irradiances $I_{1}$ and $I_{2}$ were taken at different liquid path lengths

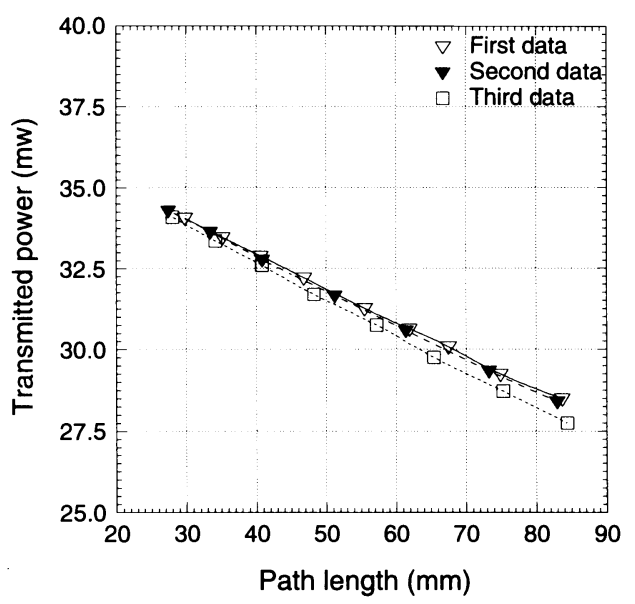

(a)

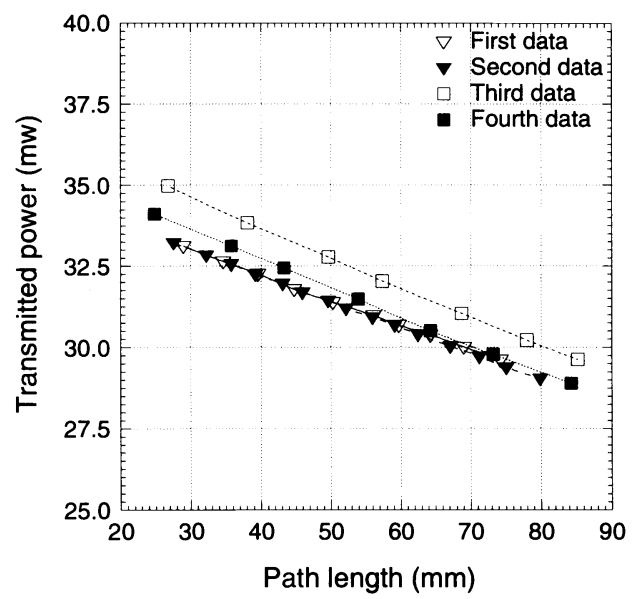

(b)

Fig. 9 Transmission power measurements for RP-1 at (a) 0.4765 $\mu \mathrm{m}$ and (b) $0.488 \mu \mathrm{m}$.

$y_{1}$ and $y_{2}$, with a path-length difference of more than $20 \mathrm{~mm}$. This was done because of the large variations of $k$ at less than $20 \mathrm{~mm}$ liquid path-length difference. Also, we measured the actual laser power at every wavelength to confirm that the laser power did not drift. As can be seen in Fig. 10(b), three sets of measurements were taken by using the collimated laser beam at $0.532 \mu \mathrm{m}$. The average value of $k$ is measured as $3.49 \times 10^{-8}$, and its standard deviation is found to be $\pm 3.17 \times 10^{-9}$. The measured average values of $k$ at 0.6328 and $1.064 \mu \mathrm{m}$ are $3.83 \times 10^{-8}$ and $3.91 \times 10^{-7}$ with standard deviations of $\pm 5.54 \times 10^{-9}$ and $\pm 1.24 \times 10^{-8}$, respectively. At $10.5915 \mu \mathrm{m}$ (Tables 4 and 5), the values of $k$ and $n_{r}$ for RP-1 are measured to be $3.53 \times 10^{-3}$ and 1.501 , respectively. Five sets of reflectance measurements were taken at $0.193 \mu \mathrm{m}$, as shown in Table 1 . The measured average value of $n_{r}$ at $0.193 \mu \mathrm{m}$ is 1.501 , and its standard deviation is \pm 0.005 . From Tables 2 and 3 , the measured $n_{r}$ of RP- 1 at $0.4765,0.488,0.5145$, and $0.532 \mu \mathrm{m}$ is $1.448,1.446$, 1.447 , and 1.439 , respectively.

At $0.193 \mu \mathrm{m}$, the accuracy of the transmission measurements with the spectrophotometer is a main source of error 


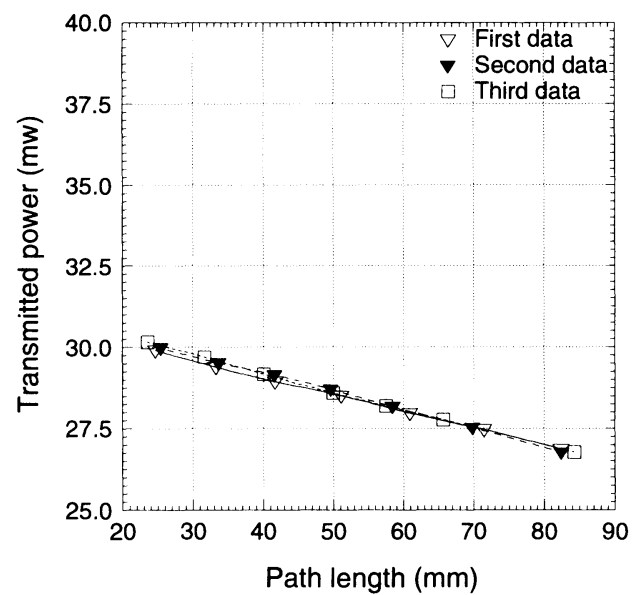

(a)

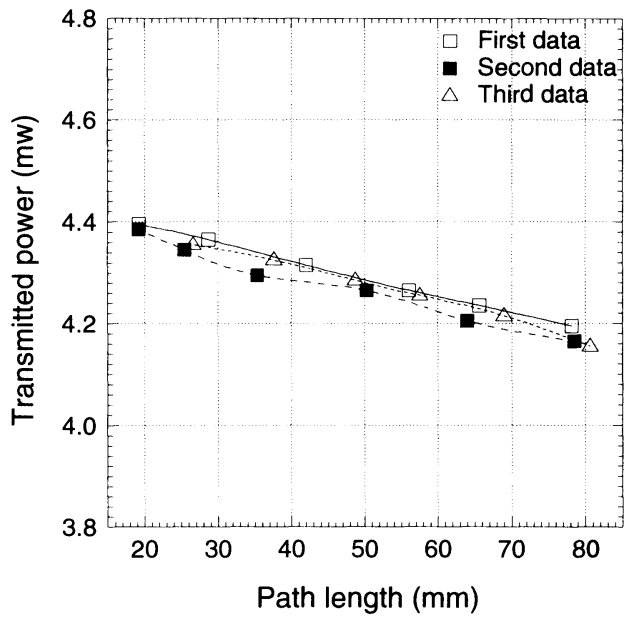

(b)

Fig. 10 Transmission power measurements for RP-1 at (a) 0.5145 $\mu \mathrm{m}$ and (b) $0.532 \mu \mathrm{m}$.

in the determination of $k$. An error of $\pm 1.97 \times 10^{-4}$ is estimated in $k$. For the critical-angle measurements, the error comes from the determination of the two angles $\phi_{0}$ and $\phi_{c}$. The error in measurement of these angles is found to be $\pm 0.05 \mathrm{deg}$. Applying this to the determination of $n_{r}$ gives an error of $\pm 0.35 \%$. The values of $n_{r}$ from Mueller-matrixelement values at 0.6328 and $1.064 \mu \mathrm{m}$ were determined as 1.445 and 1.436 with standard deviations of \pm 0.008 and \pm 0.001 , respectively. Because of the uncertainty in the Mueller matrix elements at $0.6328 \mu \mathrm{m}$, there is a high standard deviation of $n_{r}$ at $0.6328 \mu \mathrm{m}$. Error in $n_{r}$ measured at $10.5915 \mu \mathrm{m}$ is associated with the small number of fringes. There was low fringe movement as the cell was translated, due to the use of a thin cell. Considering this error gives an error of $\pm 2.4 \%$ in $n_{r}$. Inaccuracy of the power meter is a source of error in determination of $k$ at $10.5915 \mu \mathrm{m}$. An error of $\pm 0.1 \mathrm{~W}$ in transmission power gives an error of $\pm 6.94 \times 10^{-4}$ in $k$.

\section{Conclusions}

We have measured the refractive indices of liquid RP-1 at $0.193,0.4765,0.488,0.5145,0.532,0.6328,1.064$, and

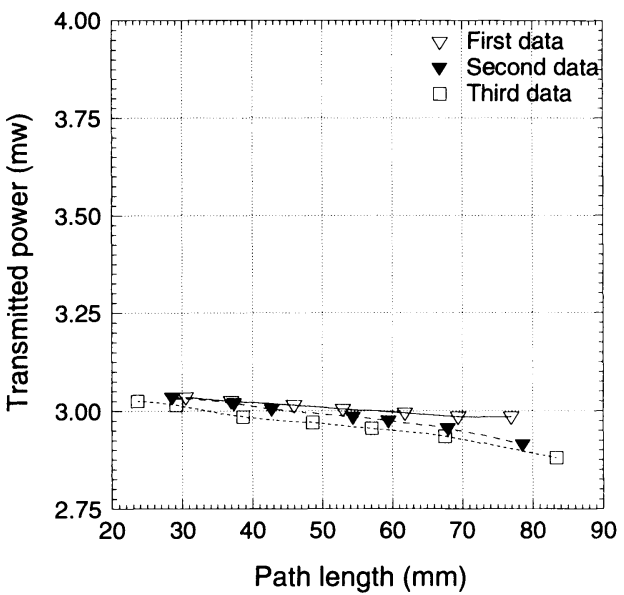

(a)

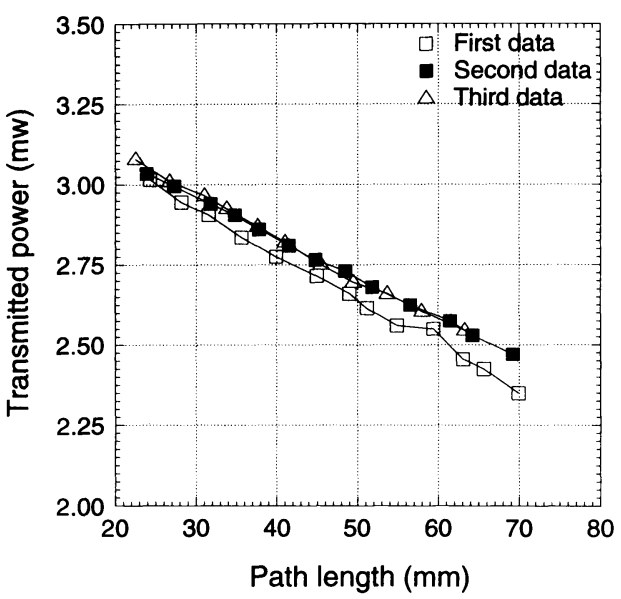

(b)

Fig. 11 Transmission power measurements for RP-1 at (a) 0.6328 $\mu \mathrm{m}$ and (b) $1.064 \mu \mathrm{m}$.

Table 1 Reflectance measurements on RP-1 and $\mathrm{H}_{2} \mathrm{O}$.

\begin{tabular}{|c|c|c|}
\hline & $\begin{array}{c}\text { Incident } \\
\text { Angle }(\theta)\end{array}$ & $\begin{array}{c}\text { Measured } \\
\text { Reflectance }\left(\mathrm{R}_{\mathrm{u}}\right)\end{array}$ \\
\cline { 2 - 3 } 1. RP-1 at $0.193 \mu \mathrm{m}$ & 0.0 & 0.039161 \\
& 4.1 & 0.040273 \\
& 5.0 & 0.040003 \\
& 5.7 & 0.040203 \\
& 6.2 & 0.040972 \\
\hline \multirow{3}{*}{ 2. Water at $0.248 \mu \mathrm{m}$} & 4.8 & 0.023440 \\
& 6.6 & 0.024300 \\
& 7.6 & 0.023444 \\
\hline
\end{tabular}

Table 2 The critical-angle measurements at $0.4765,0.488$, and $0.5145 \mu \mathrm{m}$.

\begin{tabular}{|c|c|c|c|}
\hline$\phi_{0}$ & $\phi_{\mathrm{c}}$ & $\theta_{\mathrm{c}}=2\left(\phi_{\mathrm{c}}-\phi_{0}\right)$ & $\lambda$ \\
\hline 348.08 & 372.33 & 48.5 & $\mathrm{H}_{2} \mathrm{O} @ 0.488 \mu \mathrm{m}$ \\
348.08 & 369.91 & 43.68 & $\mathrm{RP}-1 @ 0.4765 \mu \mathrm{m}$ \\
348.03 & 369.91 & 43.76 & $\mathrm{RP}-1 @ 0.488 \mu \mathrm{m}$ \\
348.03 & 369.88 & 43.7 & $\mathrm{RP}-1 @ 0.5145 \mu \mathrm{m}$ \\
\hline
\end{tabular}


Table 3 Critical-angle measurements on RP-1 at $0.532 \mu \mathrm{m}$.

\begin{tabular}{|l|c|c|c|}
\hline & $\phi_{0}$ & $\phi_{\mathrm{c}}$ & $\theta_{\mathrm{c}}=2\left(\phi_{\mathrm{c}}-\phi_{0}\right)$ \\
\cline { 2 - 4 } 1. Small aperture & 255.25 & 277.25 & 44 \\
& 255.25 & 277.25 & 44 \\
& 255.25 & 277.29 & 44.08 \\
\hline 2. Big aperture & 255.25 & 277.29 & 44.08 \\
& 255.08 & 277.08 & 44 \\
\hline
\end{tabular}

Table 4 Obtained data for $n_{r}$ measurement on RP-1 at $10.5915 \mu \mathrm{m}$.

\begin{tabular}{|c|c|c|c|c|}
\hline \multicolumn{6}{|c|}{ Wavelength $=10.5915 \mu \mathrm{m} \Delta \mathrm{S}=(0.003181) \Delta \mathrm{L}$} \\
\hline $\begin{array}{c}\text { start } \\
\mathrm{mm}\end{array}$ & $\begin{array}{c}\text { end } \\
\mathrm{mm}\end{array}$ & \# fringes & $\begin{array}{c}\Delta \mathrm{L} \\
\mathrm{mm}\end{array}$ & $\begin{array}{c}\Delta \mathrm{S} \\
\mu \mathrm{m}\end{array}$ \\
\hline 5.00 & 18.68 & 4 & 13.68 & 43.51 \\
18.35 & 5.48 & 4 & 12.87 & 40.93 \\
6.00 & 19.73 & 4 & 13.73 & 43.67 \\
20.00 & 7.00 & 4 & 13.00 & 41.35 \\
5.00 & 18.26 & 4 & 13.26 & 42.18 \\
20.00 & 6.72 & 4 & 13.28 & 42.24 \\
\hline
\end{tabular}

Table 5 The transmission power measurements on RP-1 at $10.5915 \mu \mathrm{m}$.

\begin{tabular}{|c|c|c|}
\hline \multicolumn{3}{|c|}{ Wavelength $=10.5915 \mu \mathrm{m} \Delta \mathrm{S}=(0.02703) \Delta \mathrm{L}$} \\
\hline $\begin{array}{c}\text { Distance } \Delta \mathrm{L} \\
\mathrm{mm}\end{array}$ & $\begin{array}{c}\text { Measured power } \\
\text { Watts }\end{array}$ & $\begin{array}{c}\text { Measured power } \\
\text { Watts }\end{array}$ \\
\hline 0 & 0.13 & 0.13 \\
20 & 1.25 & 1.25 \\
\hline
\end{tabular}

Table 6 Typical measured values of the Mueller matrix elements at different wavelengths and for various incident angles.

\begin{tabular}{|c|c|c|c|c|c|c|c|}
\hline \multirow{2}{*}{$\begin{array}{l}\text { Material (Wavelength) } \\
\mathrm{H}_{2} \mathrm{O}(1.064 \mu \mathrm{m})\end{array}$} & \multirow{2}{*}{$\begin{array}{c}\text { Incident Angle } \\
67^{\circ}\end{array}$} & \multicolumn{6}{|c|}{ Mueller Matrix } \\
\hline & & M & $=$ & $\begin{array}{c}1.00 \\
0.74 \\
-0.006 \\
0.03\end{array}$ & $\begin{array}{l}0.738 \\
1.002 \\
0.025 \\
0.02\end{array}$ & $\begin{array}{r}0.033 \\
-0.046 \\
0.677 \\
-0.016\end{array}$ & $\begin{array}{l}0.019 \\
0.032 \\
0.019 \\
0.684\end{array}$ \\
\hline \multirow{3}{*}{$\mathrm{RP}-1(0.6328 \mu \mathrm{m})$} & $72^{\circ}$ & $\mathrm{M}$ & $=$ & $\begin{array}{r}1.00 \\
0.576 \\
-0.009 \\
0.022\end{array}$ & $\begin{array}{l}0.576 \\
0.99 \\
0.031 \\
0.016\end{array}$ & $\begin{array}{r}-0.027 \\
-0.048 \\
0.823 \\
-0.023\end{array}$ & $\begin{array}{l}0.017 \\
0.032 \\
0.02 \\
0.825\end{array}$ \\
\hline & $57^{\circ}$ & M & $=$ & $\begin{aligned} & 1.00 \\
& 1.005 \\
&-0.033 \\
&-0.017\end{aligned}$ & $\begin{array}{l}1.004 \\
1.02 \\
-0.028 \\
-0.018\end{array}$ & $\begin{array}{r}0.054 \\
0.048 \\
0.099 \\
-0.005\end{array}$ & $\begin{array}{l}0.038 \\
0.035 \\
0.001 \\
0.097\end{array}$ \\
\hline & $60^{\circ}$ & M & $=$ & $\begin{array}{c}1.00 \\
0.972 \\
-0.037 \\
-0.023\end{array}$ & $\begin{array}{r}0.976 \\
1.013 \\
-0.022 \\
-0.016\end{array}$ & $\begin{array}{r}0.053 \\
0.036 \\
0.262 \\
-0.003\end{array}$ & $\begin{array}{l}0.037 \\
0.027 \\
0.002 \\
0.262\end{array}$ \\
\hline \multirow{5}{*}{$\mathrm{RP}-1(1.064 \mu \mathrm{m})$} & $65^{\circ}$ & M & $=$ & $\begin{array}{r}1.00 \\
0.871 \\
-0.038 \\
-0.022\end{array}$ & $\begin{array}{r}0.871 \\
1.008 \\
-0.018 \\
-0.003\end{array}$ & $\begin{array}{r}0.049 \\
0.021 \\
0.504 \\
-0.001\end{array}$ & $\begin{array}{r}0.035 \\
0.017 \\
-0.003 \\
0.505\end{array}$ \\
\hline & $70^{\circ}$ & M & $=$ & $\begin{aligned} & 1.00 \\
& 0.728 \\
&- 0.022 \\
&-0.016\end{aligned}$ & $\begin{array}{l}0.73 \\
1.012 \\
0.001 \\
0.009\end{array}$ & $\begin{array}{l}0.053 \\
0.021 \\
0.699 \\
0.002\end{array}$ & $\begin{array}{r}0.034 \\
0.015 \\
-0.004 \\
0.709\end{array}$ \\
\hline & $72^{\circ}$ & $\mathrm{M}$ & $=$ & $\begin{array}{c}1.00 \\
0.649 \\
-0.005 \\
0.03\end{array}$ & $\begin{array}{l}0.646 \\
1.001 \\
0.002 \\
0.016\end{array}$ & $\begin{array}{c}-0.027 \\
-0.044 \\
0.767 \\
-0.02\end{array}$ & $\begin{array}{l}0.021 \\
0.028 \\
0.016 \\
0.768\end{array}$ \\
\hline & $75^{\circ}$ & M & $=$ & $\begin{array}{r}1.00 \\
0.539 \\
-0.007 \\
0.023\end{array}$ & $\begin{array}{l}0.543 \\
0.996 \\
0.033 \\
0.018\end{array}$ & $\begin{array}{c}-0.024 \\
-0.038 \\
0.846 \\
-0.02\end{array}$ & $\begin{array}{l}0.017 \\
0.032 \\
0.025 \\
0.843\end{array}$ \\
\hline & $79^{\circ}$ & M & $=$ & $\begin{array}{r}1.00 \\
0.399 \\
-0.002 \\
0.013\end{array}$ & $\begin{array}{l}0.397 \\
0.995 \\
0.035 \\
0.01\end{array}$ & $\begin{array}{c}-0.016 \\
-0.035 \\
0.919 \\
-0.03\end{array}$ & $\begin{array}{l}0.011 \\
0.026 \\
0.02 \\
0.922\end{array}$ \\
\hline
\end{tabular}

Table 7 Measured refractive indices of water.

\begin{tabular}{|c|c|c|c|c|c|c|}
\hline$\lambda(\mu m)$ & $\mathrm{n}_{\mathrm{r}}$ & $\begin{array}{c}\text { Std or Est } \\
\text { error }\end{array}$ & $\mathrm{k}$ & $\begin{array}{c}\text { Std or Est } \\
\text { error }\end{array}$ & \multicolumn{2}{|c|}{ Standard values $^{10}$} \\
\cline { 6 - 7 } & & $\mathrm{n}_{\mathrm{r}}$ & $\mathrm{k}$ \\
\hline 0.248 & 1.364 & \pm 0.004 & - & - & 1.363 & $3.47 \times 10^{-8}$ \\
0.488 & 1.335 & $\pm 0.005^{*}$ & - & - & 1.336 & $9.69 \times 10^{-10}$ \\
0.6328 & 1.332 & \pm 0.002 & - & - & 1.332 & $1.47 \times 10^{-8}$ \\
1.064 & 1.328 & \pm 0.001 & $1.14 \times 10^{-6}$ & $\pm 4.25 \times 10^{-8}$ & 1.326 & $1.13 \times 10^{-6}$ \\
\hline \multicolumn{6}{|c|}{ Std=Standard deviation: ${ }^{*}=$ Estimated error. } \\
\hline
\end{tabular}

Table 8 Measured refractive indices of RP-1 at various wavelengths.

\begin{tabular}{|c|c|c|c|c|}
\hline$\lambda(\mu m)$ & $\mathrm{n}_{\mathrm{r}}$ & $\begin{array}{c}\text { Std or Est } \\
\text { error }\end{array}$ & $\mathrm{k}$ & $\begin{array}{c}\text { Std or Est } \\
\text { error }\end{array}$ \\
\hline 0.193 & 1.501 & \pm 0.005 & $1.26 \times 10^{-3}$ & $\pm 1.97 \times 10^{-4 *}$ \\
0.4765 & 1.448 & $\pm 0.005^{*}$ & $1.31 \times 10^{-7}$ & $\pm 5.49 \times 10^{-9}$ \\
0.488 & 1.446 & $\pm 0.005^{*}$ & $1.01 \times 10^{-7}$ & $\pm 6.07 \times 10^{-9}$ \\
0.5145 & 1.447 & $\pm 0.005^{*}$ & $7.86 \times 10^{-8}$ & $\pm 4.01 \times 10^{-9}$ \\
0.532 & 1.439 & $\pm 0.005^{*}$ & $3.49 \times 10^{-8}$ & $\pm 3.17 \times 10^{-9}$ \\
0.6328 & 1.445 & \pm 0.008 & $3.83 \times 10^{-8}$ & $\pm 5.54 \times 10^{-9}$ \\
1.064 & 1.436 & \pm 0.001 & $3.91 \times 10^{-7}$ & $\pm 1.24 \times 10^{-8}$ \\
10.5915 & 1.501 & $\pm 0.036^{*}$ & $3.53 \times 10^{-3}$ & $\pm 6.94 \times 10^{-4 *}$ \\
\hline \multicolumn{5}{|c|}{ Std=Standard deviation: ${ }^{*}=$ Estimated error. } \\
\hline \multicolumn{5}{|c}{}
\end{tabular}

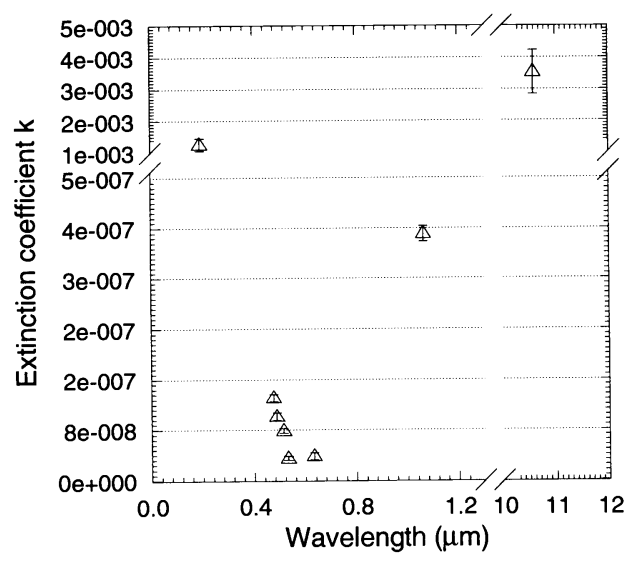

(a)

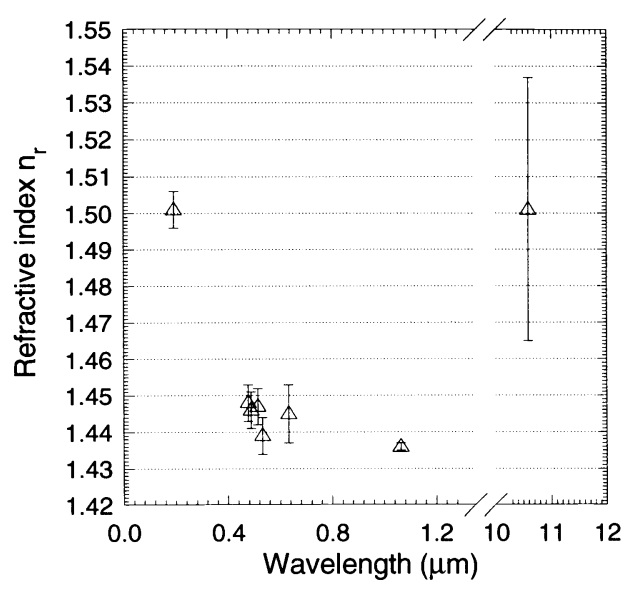

(b)

Fig. 12 Measured refractive indices of RP-1 at various wavelengths. 
$10.5915 \mu \mathrm{m}$ by using five different methods. Five methods were required as a result of the large variation in the imaginary part of the refractive index as well as for access to various laser lines. For the imaginary part of the refractive index, we used transmission power measurements at all of the wavelengths. For the real part of the refractive index, we used reflectance measurements at $0.193 \mu \mathrm{m}$, critical-angle measurements at $0.4765,0.488,0.5145$, and $0.532 \mu \mathrm{m}$, Mueller matrix elements along with ellipsometric relations at 0.6328 and $1.064 \mu \mathrm{m}$, and Michelson interferometric measurements at $10.5915 \mu \mathrm{m}$. Refractive indices of water were measured as a check on the accuracy of the measurement techniques and were found to be in good agreement with standard values. $^{11}$

\section{Acknowledgments}

This work was partially supported under NASA Lewis Research Center grant NAG-31261. The support of the Center for Electro-Optics at the University of Nebraska is also acknowledged, and we thank Dr. Bahar for the use of the scatterometer.

\section{References}

1. B. W. Grange,W. H. Stevenson, and R. Viskanta, "Refractive index of liquid solutions at low temperatures: an accurate measurement," Appl. Opt., 15(4), 858-859 (1976).

2. W. Mahmood bin Mat Yunus and Azizan bin Abdul Rahman, "Refractive index of solutions at high concentrations," Appl. Opt. 27(16), 3341-3343 (1988); (E)28(13), 2465 (1989).

3. E. Moreels, C. de Greef, and R. Finsy, "Laser light refractometer," Appl. Opt. 23(17), 3010-3013 (1984).

4. S. Sainov and N. Dushkina, "Simple laser microrefractometer," Appl. Opt. 29(10), 1406-1408 (1990).

5. R. M. A. Azzam, "Explicit determination of the complex refractive index of an absorbing medium from reflectance measurements at and near normal incidence," J. Opt. Soc. Am. 72(10), 1439-1440 (1982).

6. W. Leupacher and A. Penzkofer, "Refractive-index measurement of absorbing condensed media,' Appl. Opt. 23(10), 1554-1558 (1984).
7. Y. Lu and A. Penzkofer, "Optical constant measurements of strongly absorbing media," Appl. Opt. 25(2), 221-225 (1986).

8. O. Hunderi, "New method for accurate determination of optical constants,"' Appl. Opt. 11(7), 1572-1578 (1972).

9. W. A. Shurcliff, Polarized Light, I st ed., Chap. 8, pp. 109-123, Harvard Univ. Press, Cambridge, MA(1966)

10. R. M. A. Azzam and N. M. Bashara, Ellipsometry and Polarized Light, lst ed., North Holland, Amsterdam (1977).

11. G. M. Hale and M. R. Querry, "Optical constants of water in the 200 $\mathrm{nm}$ to $200 \mu \mathrm{m}$ wavelength region,' Appl. Opt. 12(3), 555-562 (1973).

Dennis R. Alexander received his $\mathrm{PhD}$ in nuclear engineering from Kansas State University in 1976. He currently is a professor of electrical engineering and holds a Kingery Professorship at the University of Nebraska. He is also director of the Center for Electro-Optics. His research interests include laser diagnostics and measurements, production of nanostructures using femtosecond lasers, linear and nonlinear laser interaction with aerosols, and particle sizing using light scattering instrumentation. He has authored or coauthored more than 100 scientific articles.

Ramu Kalwala received his MS degree in mechanical engineering from the University of Nebraska in 1994. This paper is a part of his master's thesis. Kalwala currently is an engineer with Caterpillar in Peoria, Illinois. Kalwala was associated with the Center for ElectroOptics.

Robert D. Kubik received his PhD from the University of Nebraska in 1993. While associated with the Center for Electro-Optics, he worked extensively with the bistatic scatterometer. His research dealt with scattering from rough surfaces and the corresponding Mueller matrix determination using a TMA scatterometer. Kubik is currently employed by Motorola in Phoenix, Arizona.

Scott A. Schaub received his PhD from the University of Nebraska in 1991. During the period after his PhD he served as a research associate in the Center for Electro-Optics performing optical measurements. Schaub is currently employed with Schuller Internationa in Littleton, Colorado. 